\title{
Ambient pressure x-ray photoelectron spectroscopy setup for synchrotron-based in situ and operando atomic layer deposition research
}

Kokkonen, E.

2022-01-01

Kokkonen , E , Kaipio , M , Nieminen , H -E , Rehman , F , Miikkulainen , V , Putkonen , M , Ritala , M , Huotari , S , Schnadt , J \& Urpelainen , S 2022 , ' Ambient pressure x-ray photoelectron spectroscopy setup for synchrotron-based in situ and operando atomic layer deposition research ' , Review of Scientific Instruments , vol. 93 , no. 1, 013905 . https://doi.org/10.1063/5.0076993

http://hdl.handle.net/10138/338858

https://doi.org/10.1063/5.0076993

cc_by

publishedVersion

Downloaded from Helda, University of Helsinki institutional repository.

This is an electronic reprint of the original article.

This reprint may differ from the original in pagination and typographic detail.

Please cite the original version. 


\section{Ambient pressure x-ray photoelectron spectroscopy setup for synchrotron- based in situ and operando atomic layer deposition research}

Cite as: Rev. Sci. Instrum. 93, 013905 (2022); https://doi.org/10.1063/5.0076993

Submitted: 29 October 2021 • Accepted: 28 December 2021 • Published Online: 10 January 2022

(D) E. Kokkonen, (D) M. Kaipio, (D) H.-E. Nieminen, et al.
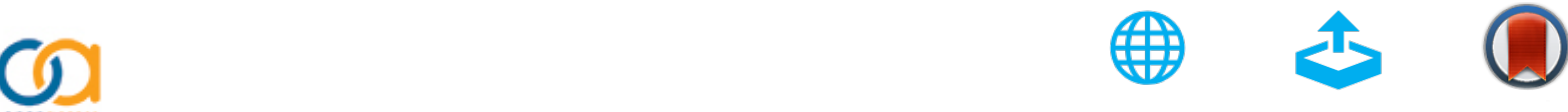

View Online

Export Citation

\section{ARTICLES YOU MAY BE INTERESTED IN}

A setup for studies of photoelectron circular dichroism from chiral molecules in aqueous solution

Review of Scientific Instruments 93, 015101 (2022); https://doi.org/10.1063/5.0072346

Cylindrical metal liner implosion at extremes of pressure and material velocity on an intense pulsed power facility-FP-2

Review of Scientific Instruments 93, 013904 (2022); https://doi.org/10.1063/5.0064238

A new technique for tokamak edge density measurement based on microwave interferometer

Review of Scientific Instruments 93, 013502 (2022); https://doi.org/10.1063/5.0074838
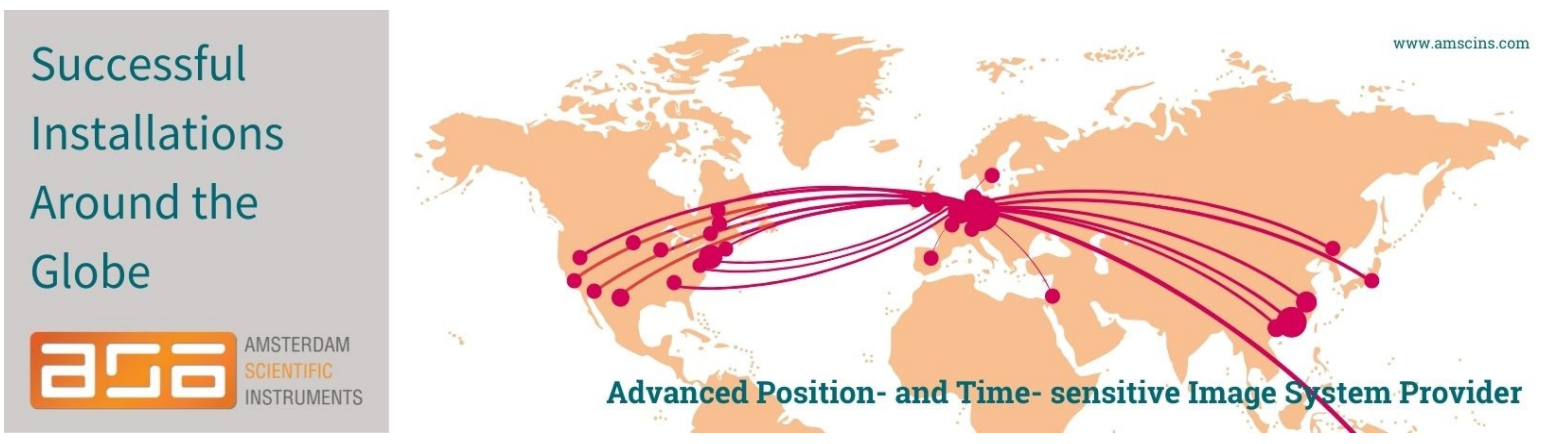


\title{
Ambient pressure x-ray photoelectron spectroscopy setup for synchrotron-based in situ and operando atomic layer deposition research
}

\author{
Cite as: Rev. Sci. Instrum. 93, 013905 (2022); doi: 10.1063/5.0076993 \\ Submitted: 29 October 2021 • Accepted: 28 December 2021 • \\ Published Online: 10 January 2022
}
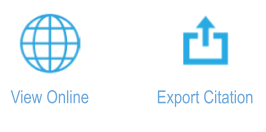

\begin{abstract}
E. Kokkonen, ${ }^{1, a)}$ (iD M. Kaipio, ${ }^{2}$ (D) H.-E. Nieminen, ${ }^{2}$ (D) F. Rehman, ${ }^{3}$ V. Miikkulainen, ${ }^{4}$ (D) M. Putkonen, ${ }^{5}$
M. Ritala, ${ }^{5}$ (D) Suotari, ${ }^{6}$ (D) J. Schnadt, ${ }^{1,7}$ (D) and S. Urpelainen ${ }^{8}$

AFFILIATIONS

${ }^{1}$ MAX IV Laboratory, Lund University, Box 118, 221 o0 Lund, Sweden

${ }^{2}$ Department of Chemistry, University of Helsinki, Fl-00014 Helsinki, Finland

${ }^{3}$ Division of Synchrotron Radiation Research, Department of Physics, Lund University, P.O. Box 118, 22100 Lund, Sweden

${ }^{4}$ Department of Chemistry and Materials Science, Aalto University, 00076 Aalto, Finland

${ }^{5}$ Department of Chemistry, University of Helsinki, 00014 Helsinki, Finland

${ }^{6}$ Department of Physics, University of Helsinki, 00014 Helsinki, Finland

${ }^{7}$ Division of Synchrotron Radiation Research, Department of Physics, Lund University, Box 118, 22100 Lund, Sweden

${ }^{8}$ Nano and Molecular Systems Research Unit, University of Oulu, 90014 Oulu, Finland
\end{abstract}

a) Author to whom correspondence should be addressed: esko.kokkonen@maxiv.lu.se

\begin{abstract}
An ambient pressure cell is described for conducting synchrotron-based x-ray photoelectron spectroscopy (XPS) measurements during atomic layer deposition (ALD) processes. The instrument is capable of true in situ and operando experiments in which it is possible to directly obtain elemental and chemical information from the sample surface using XPS as the deposition process is ongoing. The setup is based on the ambient pressure XPS technique, in which sample environments with high pressure (several mbar) can be created without compromising the ultrahigh vacuum requirements needed for the operation of the spectrometer and the synchrotron beamline. The setup is intended for chemical characterization of the surface intermediates during the initial stages of the deposition processes. The SPECIES beamline and the ALD cell provide a unique experimental platform for obtaining new information on the surface chemistry during ALD half-cycles at high temporal resolution. Such information is valuable for understanding the ALD reaction mechanisms and crucial in further developing and improving ALD processes. We demonstrate the capabilities of the setup by studying the deposition of $\mathrm{TiO}_{2}$ on a $\mathrm{SiO}_{2}$ surface by using titanium(IV) tetraisopropoxide and water as precursors. Multiple core levels and the valence band of the substrate surface were followed during the film deposition using ambient pressure XPS.

(C) 2022 Author(s). All article content, except where otherwise noted, is licensed under a Creative Commons Attribution (CC BY) license (http://creativecommons.org/licenses/by/4.0/). https://doi.org/10.1063/5.0076993
\end{abstract}

\section{INTRODUCTION}

Atomic layer deposition (ALD) ${ }^{1}$ is a variant of the chemical vapor deposition (CVD) technique for depositing thin films. With $\mathrm{ALD}$, it is possible to create highly uniform and conformal films even on high-aspect-ratio structures. ${ }^{2}$ The film thickness can be controlled on the atomic level due to the self-limiting nature of the layer deposition. Even though ALD processes for many materials are well established, the details of the surface reactions and their role in defining the film structure and quality remain largely unknown. In contrast to CVD techniques, where the growth proceeds with all the precursors simultaneously present in the gas phase, ALD precursor pulses are separated from each other and the film growth occurs only through reactions between the gas phase precursor and reactive groups on the substrate surface. The precursor pulses can be separated either temporally (pulses occur at different times with 


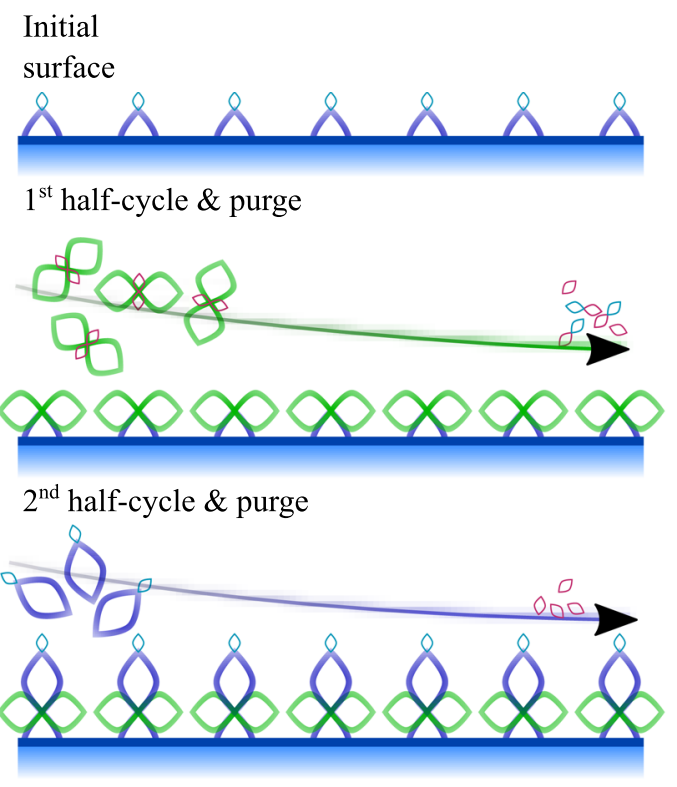

FIG. 1. Schematic example of the self-limiting nature of two alternating ALD half-cycles.

a purge sequence in between) or spatially (the substrate is moved between different areas with continuous precursor flows with areas of inert gas purging in between).

Temporal ALD processes employ a step-wise precursor introduction scheme: If two precursors are used, the ALD process typically consists of the following steps: (1) first precursor pulse, (2) purge, (3) second precursor pulse, and (4) purge (Fig. 1). The process cycle is divided into the first half-cycle, which consists of first precursor pulse and purge, and the second half-cycle, which consists of the second precursor pulse and purge. Together, the half-cycles make up one full ALD cycle. The reaction cycles are repeated as many times as necessary in order to reach a desired film thickness.

In order to truly understand the underlying chemistry that occurs during the initial half-cycles, it is imperative to obtain information from the surface during ALD. Typically, investigations aiming at providing such information are classified as either ex situ or in situ studies. The former type refers to scenarios where the ALD reactor is physically separated from the experimental apparatus, requiring exposure of the sample to air in between the deposition and the characterization. A setup where the ALD reactor is a part of the same characterization system but still separate from the analysis chamber by a vacuum valve, is often called an in vacuo system. This kind of setup allows studying the surfaces between each half-cycle without exposure to air. Some experimental techniques might allow us to acquire information from the surface during the deposition, in which case the methodology is called an in situ experiment. The terminology is not universal, however, and in the past, experiments that have been labeled in situ would have been more appropriately described with an in vacuo label.

Some of the most common in situ tools that are used to obtain information on ALD processes are quartz crystal microbalance (QCM), ${ }^{6,7}$ mass spectrometry, ${ }^{8,9}$ spectroscopic ellipsometry, ${ }^{10}$ and, recently also, atomic force microscopy. ${ }^{11}$ To study surface components and termination of the substrate, infrared spectroscopy, in particular, Fourier transform infrared spectroscopy (FTIR), ${ }^{12-16}$ has seen interest. These techniques provide information on the ALD reaction mechanism through measurement of various quantities either in the gas phase or more directly on the surface. An extensive review of in situ methods has been conducted earlier ${ }^{2}$ and we will not focus on them here any further.

X-ray photoelectron spectroscopy (XPS) has been an invaluable tool for ALD film investigations for decades. ${ }^{17-24}$ It has been mostly used with laboratory x-ray sources, but some work has been done with synchrotron sources as well. Due to the high surface sensitivity, elemental specificity, and chemical sensitivity of XPS, it is essential in unraveling the details of the chemistry of the surface layers, precursor bonding schemes, and ligand-exchange models. In XPS, the binding energies of the core or valence electrons are measured. The core electron binding energies are especially sensitive to the chemical environment created by the neighboring atoms, thereby giving an accurate view of how the surface structures are chemically created. Information on surface oxidation state changes is also important for studies of ALD processes as many of them occur through redox reactions. On the other hand, valence bands (VBs) also give information on the bonding schemes as well as view into the density of states of the surface.

ALD experiments using XPS have been typically challenging or even impossible to perform in situ due to the high vacuum conditions required for conventional XPS. In this work, we have used ambient pressure XPS (APXPS) to overcome the highvacuum pressure requirements and present a novel APXPS sample environment specifically designed for ALD, which allows for true in situ and operando synchrotron-based XPS studies of ALD processes as they happen. We have chosen to append the operando term to our work, as it very well encapsulates the idea behind the experiment, which is to perform the measurements while the deposition is on-going.

Synchrotron radiation, due to its high brilliance and other favorable qualities such as accurate energy tunability, opens up the possibility for conducting a plethora of experiments to further broaden in situ ALD studies. ${ }^{24}$ The most common techniques used to study ALD with synchrotron radiation are $\mathrm{x}$-ray reflectivity $(\mathrm{XRR})^{25-31}$ to obtain information on film thickness, roughness, and density, $\mathrm{x}$-ray diffraction (XRD) ${ }^{32,33}$ to obtain information on phase orientation and size of crystallites, and $\mathrm{x}$-ray fluorescence $(\mathrm{XRF})^{34-37}$ to get information on elemental composition. Other techniques include grazing incidence small angle $\mathrm{x}$-ray scattering (GISAXS), ${ }^{27,36,37}$ and SAXS in general, for morphology and roughness measurements and $\mathrm{X}$-ray absorption spectroscopy (XAS) $)^{18,31,38,39}$ and extended x-ray absorption fine structure (EXAFS) for composition and local atomic environment investigations.

In the past (half) decade, the field of synchrotron-based APXPS has developed more toward studying ALD using operando measurements. ${ }^{40}$ Since APXPS allows for conducting XPS measurements at elevated pressures (up to several tens mbar or in special instruments even atmospheric pressures ${ }^{41}$ ) in pressure and temperature regimes that are very similar to those of commercial ALD reactors, it is an excellent tool for in situ and operando ALD reaction studies. Several papers on the subject have already been published using standard 
APXPS setups, ${ }^{42-49}$ and experiments are increasing in frequency. While the previous works have revealed novel insight into the first steps of ALD, they often suffer from a sub-optimal reactor design, such as a shared gas line for all precursors. This has served as a motivation for our present work: the implementation of a dedicated synchrotron-based APXPS setup for ALD research.

As an example, some previous studies involving operando XPS focused on investigating the surface chemistry of thermal ALD of $\mathrm{TiO}_{2}$ and $\mathrm{HfO}_{2}$ with water as the oxygen precursor and $\mathrm{Ti}$ and Hf alkylamido complexes as the metal precursors. In the literature, these ALD processes have been so far proposed to follow a unimolecular two-step ligand-exchange mechanism releasing alkylamine. ${ }^{50,51}$ However, as the new studies have provided information during the ALD process, the ligand-exchange mechanism was revised. ${ }^{5}$ Another important result was for the ALD of $\mathrm{HfO}_{2}$ on InAs: it has been found that the substrate plays an active role as a source of oxygen during the very first metal half-cycle. ${ }^{48}$ These findings play an important role in developing reaction models of ALD, especially in the sub-cycle timescale.

Here, we report on the development of an APXPS sample environment for true in situ and operando XPS studies on atomic layer film deposition. We call this sample environment "the ALD cell." Its design details are given and the characteristic features which distinguish it from the previous in situ systems are elaborated. The setup can be used to study ALD reactions under similar conditions as in commercial ALD reactors, and it is installed at the SPECIES beamline $e^{53,54}$ at the MAX IV Laboratory in Lund, Sweden. The beamline provides a wide energy range of 30-1500 eV, allowing for XPS measurements at most core levels with surface-sensitive energies while also providing a unique access to valence band measurements at a high photon flux.

\section{PRINCIPLES OF THE ALD REACTOR DESIGN}

In principle, an ALD system consists of relatively few parts: only a reaction chamber with at least two precursor inlet lines is needed together with a pumping line to evacuate the chamber and a substrate heating system. In practice, however, there are many significant engineering challenges that need to be resolved. The main considerations are as follows:

Heating of the substrate and the deposition chamber: Almost every ALD process is performed at an elevated temperature in order to attain faster reaction kinetics and often also larger film thickness per cycle. Nearly always, a deposition temperature higher than room temperature leads to a better film quality. ${ }^{55}$ ALD reaction chambers are either hot-wall (the substrate and chamber are heated) or cold-wall (only the substrate is heated). A cold-wall design may be simpler but runs a risk of inadequate removal of excess precursors from the chamber, as low-vapor pressure precursors and gaseous reaction products may adsorb and condense on the chamber walls. These design choices may also affect the reactions occurring on the substrate-gas interface because the thermodynamics of the process are affected by both the thermal energy of the precursor molecules (temperature of the gas) and the thermal energy of the surface groups (substrate temperature). Additional energy, such as plasma or radicals, can be used as well, but in such cases, some of the film conformality is sacrificed. ${ }^{56,57}$

Precursor delivery and precursor line heating: Lower-vapor pressure precursors are evaporated by heating to ensure gas phase transport to the substrate. In order to minimize precursor condensation on the walls of the delivery lines, they require a proper thermal gradient with minimized cold spots. The precursor transportation is often improved by using a carrier gas, which helps to carry the precursor molecules into the reaction chamber. ${ }^{57}$

Effective pumping, purging, and flow dynamics: In order to separate the precursor pulses from each other, the precursor lines and the reaction cell volume need to be pumped and preferably purged with an inert gas. In order to make ALD fast, reactors are often designed to work in the laminar gas-flow regime. ${ }^{58}$ The precursor lines can be used also as the purging gas lines, or the purging and carrier gas line can be separate. Under optimized conditions, an ALD reactor can be operated with cycle times well below 1 s. ${ }^{55,56}$

With the above mentioned considerations, a successful precursor separation can be achieved, which ensures that the ALD growth conditions are reached. Precursor separation is also important in the gas lines, in which any ALD precursors that react with each other in the gas phase or on the surfaces may lead to unwanted film growth on the line walls, which, in the worst case, can lead to particle formation and blocking of the lines. ${ }^{56}$

\section{A. Design of the SPECIES ALD cell}

Based on the considerations above and requirements for a typical ALD reactor, some core design principles for the ALD cell were fixed as follows:

1. The design should conform with the design of typical ALD reactors with their gas flow dynamics and heating.

2. The cell should not differ too much from the other AP cells in use at the SPECIES beamline.

3. The complete setup should be easily adjustable for different types of experiments.

These principles were used to guide the design of the cell. A precursor delivery source was constructed for the purpose of providing pulses of precursor vapors in a well-defined manner. The cell consists of two inlet lines so that two precursor gases can be delivered into the cell without mixing before making contact with the substrate surface. Both inlet lines are made out of $\sim 6 \mathrm{~mm}$ tubing pointing directly toward the substrate surface. A pumping line is installed on the opposite side of the substrate so that the gases would be efficiently removed after they have interacted with the surface, and a laminar-like flow would form over the substrate. Figure 2 shows a computer rendering of the cell with Fig. 2(b) showing details of the substrate region and the position of the gas tubes. A schematic view of the gas inlets and outlets in the entire cell is presented in Fig. 3.

The metal precursor source in the current setup (Fig. 3) has two pneumatic valves which facilitate carrier gas flow into and out from the precursor container. Between the pneumatic valves, there is an orifice, which restricts the carrier gas flow. When the metal precursor source is at the closed state, both of the pneumatic valves are closed toward the bottle and carrier gas flows through them, 


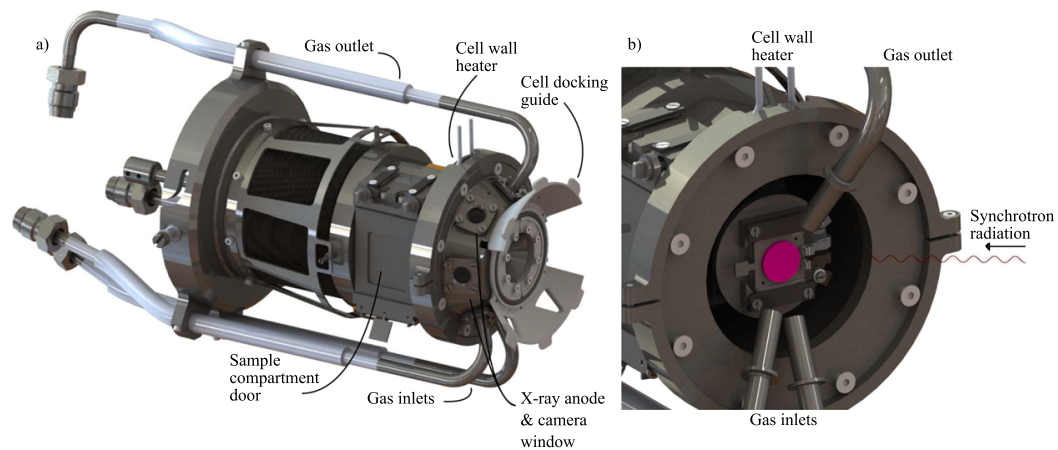

FIG. 2. (a) Computer rendering of the cell. (b) View of the substrate stage with the front part of the cell removed (sample in red) showing the position of the gas tubes and the pumping line (see Fig. 3 for a schematic view).

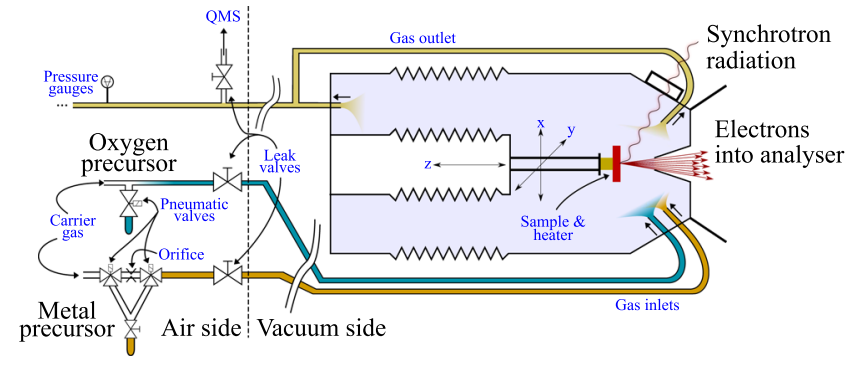

FIG. 3. A schematic view of the ALD cell showing the geometry of the gas lines and the sample with respect to the synchrotron radiation and the electron analyzer. The figure is not to correct scale. The placement of the ALD sources can be customized according to user demands on the air side, and different sources can be easily installed. The pressure (and flow) in the cell is determined using the inlet leak valves. The inner sample stage and outer cell consists of bellows which are designed to allow accurate sample positioning in $\mathrm{x}, \mathrm{y}$, and $\mathrm{z}$ directions.

bypassing the precursor bottle. When both pneumatic valves are opened, the carrier gas also enters the precursor bottle. Due to the orifice-restricted flow between the pneumatic valves, part of the carrier gas now flows through the precursor bottle in order to pick up the vaporized precursor with the carrier gas flow. Partial pressure of the precursor vapor in this gas mixture can be adjusted by changing the orifice size and controlling the precursor temperature. This facilitates a lower source temperature than with the standard one-pneumatic valve sources (similar to the current oxygen precursor source), where the precursor vapor pressure has to exceed the carrier line pressure. A metal precursor source of this design is beneficial, especially for low-vapor pressure and temperature-sensitive precursors.

The synchrotron radiation enters the cell through a thin membrane window separating the higher pressure inside the cell from the rest of the beamline. Several membrane materials are available, depending on the users' demands. Typically a $200 \mathrm{~nm}$ thick Al membrane is used. The membrane material places some restrictions on the usable $\mathrm{x}$-ray photon energy, since photons with certain energies are absorbed strongly by the material. The window is also the main constraint for the maximum pressure that can be created inside the ALD cell. The current design allows for a maximum pressure of $\sim 20$ mbar inside the cell while maintaining high-vacuum conditions on the outside.
To detect electrons from the sample, an aperture is required for reducing the amount of gas that enters the electron analyzer while simultaneously allowing high electron transmission. The design of the ALD cell follows the typical settings for other AP cells using the cell-in-cell method. ${ }^{59-62}$ A small conical aperture is placed inside the cell, which separates the cell and the first differentially pumped stage of the analyzer. Different cone aperture sizes are available, and typically cones with an aperture diameter of 0.3 or $0.5 \mathrm{~mm}$ are used. The choice of the size of the cone is dictated by the pressure requirement of the experiment and the transmission of electrons.

To conform with the demand of heated precursor lines, the ALD cell inlet lines have an in-vacuum heating system. The tubes are wrapped with a heating element (Thermocoax), enabling heating up to a temperature of about $200^{\circ} \mathrm{C}$. A similar heater is also placed on the walls of the cell near the sample stage, which makes it possible to heat a portion of the cell walls near the sample stage. The location of the cell wall heater is indicated in Fig. 2(a). Together, these heaters are expected to help eliminate cold spots and help in transporting the precursors onto the substrate. The substrate itself is heated by a resistive $\mathrm{Pt}$ wire within an alumina enclosure (Heatwave Labs, Inc. button heater model No. 101275) placed underneath the sample. The button heater is capable of high temperature heating, but in the ALD cell, the maximum allowable temperature is $\sim 400^{\circ} \mathrm{C}$ in order to protect the nearby o-rings.

The cell has many of the same properties as the other cells in use at the SPECIES beamline. ${ }^{54}$ The sample can be moved in three orthogonal directions in order to select different spots on the sample surface and to avoid $\mathrm{x}$-ray induced damage. Samples are introduced to the cell through a door and are transferred inside the vacuum using a wobble stick, which is also used as a screwdriver to close the door of the cell. The analysis chamber also has a sample garage for storing up to three samples in an UHV environment for fast switching of samples.

In order to gain information on the gas-phase products that are released during ALD, the endstation is also equipped with a quadrupole mass spectrometer (QMS). The outlet (pump) line of the cell is connected to the QMS chamber through a leak valve. The QMS chamber is located $\sim 1.5 \mathrm{~m}$ downstream from the AP cell, and therefore, only gas phase species with a long residence time can be observed. The QMS is useful in correlating the appearance of reaction products with changes seen with the $\mathrm{x}$-ray photoelectron (XP) spectra when both spectrometers are operated in the time-resolved mode. 
Recent work by Redekop et al. ${ }^{49}$ showed that another ambient pressure cell at the SPECIES beamline can be used for pulsed gas injections and synchronized data acquisition. The study shows that the reactions in the cell are mostly characterized by being in the mass-transport limit and that the setup is not suitable for exploring reaction kinetics as such. Although the same consideration is likely also true for the ALD cell, we stress that the setup described in this paper is mostly intended for chemical identification of surface species that form during the ALD reaction steps and their evolution. Indeed, the main information that this instrument brings available is surface chemistry during the ALD reactions, which is complementary information to ex situ and in vacuo XPS experiments.

It should be noted that while typical ALD reactors can be operated with cycle times in the order of a few seconds, this is not necessarily desirable for in situ and operando experiments with the ALD cell. In fact, it is often preferable to elongate the half-cycles in order to capture the changes in the surface chemistry with adequate time-resolution in the XPS measurement. The spectrometer itself can operate at even faster time scales approaching milliseconds, but in practice, this requires rather strong photoelectron signal intensities. This might not be possible to achieve especially during the initial half-cycles when only a small amount of material is present on the surface. The cycle lengths can be elongated by limiting the flow of the precursor vapor into the cell by using a precision leak valve. In the experiment showcased in this paper, the typical time scales for one half-cycle range from several minutes to $30 \mathrm{~min}$.

It is likely that the inner surfaces of the cell and the gas tubes will, over time, get coated with different materials that are used in the experiments. Prior to every experiment, the whole system is thoroughly baked to remove any loosely bound contaminants and residual water from the surfaces. Most components of the cell (especially the gas tubes) have been designed with easy exchangeability in mind. In case of irreversible contamination, which would affect the experimental results, new parts can be installed easily.

The electron spectrometer can be operated in two modes: normal XP spectra are recorded in the so-called swept mode and time-resolved XP spectra are recorded in what is called the snapshot mode. In the snapshot mode, the voltages of the analyzer are kept constant, and all electrons with kinetic energies within a specified energy range are counted. Thereby, the snapshot mode allows us to record time-resolved spectra with subsecond temporal resolution since no time is spent in changing the voltages or averaging out the detector sensitivity. The energy range that can be captured in a single snapshot is determined by the pass energy of the analyzer, which, in turn, determines the electron energy resolution for a given entrance slit. For example, the typically used pass energies of 50 and $100 \mathrm{eV}$ together with $1 \mathrm{~mm}$ entrance slit yield energy resolutions of $\sim 0.17$ and $0.5 \mathrm{eV}$, respectively. It is often desirable to measure several core levels at the same time in the snapshot mode, in which case they are recorded in series. The more energy windows need to be captured, the slower the acquisition becomes as time is needed to change voltages between each energy window. Often, after completing each half-cycle, more thorough spectra with higher signal-to-noise ratio are measured using the swept mode as time is no longer a concern. This is also the case for all experiments presented in this paper. In the swept mode, any given electron energy range can be measured by scanning the voltages of the analyzer. The spectra recorded in the swept mode take longer time to acquire, but in addition to the increased energy range, one can also use lower pass energies and entrance slits to achieve higher resolution.

Several standard in-vacuum sample preparation tools are available at the APXPS endstation. Methods include an $\mathrm{Ar}^{+}$ion sputter gun, possibility for UHV annealing, gas dosing at low pressures (up to $1 \cdot 10^{-5} \mathrm{mbar}$ ), possibility for evaporating metals on surfaces, and inspecting the quality of surfaces using a low energy electron diffraction (LEED) instrument. The main instrument of the endstation is the SPECS NAP150 electron spectrometer. More details on the endstation and the beamline are available elsewhere. ${ }^{53,54}$

\section{RESEARCH EXAMPLE: $\mathrm{TiO}_{2}$ DEPOSITED ON NATIVE OXIDE-COVERED Si}

To demonstrate the capabilities and possibilities that the ALD cell has to offer, several experiments were performed during the commissioning phase of the cell. Here, we will present one of them: the ALD of $\mathrm{TiO}_{2}$ on a $\mathrm{SiO}_{2}$ substrate from titanium tetraisopropoxide (TTIP) and water as the two precursors. This experiment is a proof-of-principle demonstration, intended to showcase the results that can be obtained using the ALD cell.

Titanium dioxide is a material of high technological interest due to its photocatalytic, dielectric, and transparent-conductor features that differ between the crystal phases. ${ }^{63}$ The ALD of $\mathrm{TiO}_{2}$ has been studied widely ${ }^{64}$ on different surfaces and using various precursors. $\mathrm{TiO}_{2}$ is one of the few materials for which the ALD has already been studied by operando APXPS. ${ }^{43,45}$

TTIP $\left(\mathrm{Ti}\left(\mathrm{OCH}\left(\mathrm{CH}_{3}\right)_{2}\right)_{4}\right)$ was obtained from Sigma-Aldrich (purity 99.999\%) and used as delivered. Deionized water was purified by freeze-pump-thaw cycles prior to the experiment. The TTIP container was heated to about $50{ }^{\circ} \mathrm{C}$, while the water was kept at room temperature. A (100) silicon with a native oxide was used as the substrate and it was introduced into the vacuum and into the ALD cell with no additional cleaning. The depositions were carried out with the substrate at $170{ }^{\circ} \mathrm{C}$. The total pressure in the cell during the time-resolved measurements was $\sim 0.25 \mathrm{mbar}$, which is due to the Ar carrier gas and the precursor vapor pressure.

$\mathrm{X}$-ray photoelectron (XP) spectra were measured during the TTIP and water pulses in the snapshot mode and after the pulses in the swept mode. During the snapshot measurements, the Ti $2 p, \mathrm{O} 1 \mathrm{~s}$, $\mathrm{C} 1 \mathrm{~s}$, and Si $2 \mathrm{p}$ core levels were followed. The snapshot mode measurement was always continued until the changes in the spectra were minimal (i.e., until saturation of the surface was achieved). After reaching the saturation, swept-mode spectra were acquired at different photon energies to get a better overview of the chemical state of the surface. The swept spectra were acquired with the Ar carrier gas present in the cell at a total pressure of $\sim 0.1 \mathrm{mbar}$. The snapshot mode spectra were not energy calibrated, but the Ti $2 \mathrm{p}$ swept mode spectra were calibrated to each other so that the $\mathrm{Ti}^{4+}$ peak was consistent. Any ambiguity in the energy calibration accuracy is taken into account in the data interpretation.

\section{A. Experimental results}

Before any gas doses and after heating the Si substrate to $170^{\circ} \mathrm{C}$, reference spectra were measured to ensure that the surface did not 
have any traces of Ti on it. In the initial stages of the deposition, TTIP was pulsed several times onto the surface with no obvious changes in the spectra. Even with an extremely long TTIP pulse (nearly $2 \mathrm{~h}$ ), no Ti signal was seen in the spectra. Eventually, approximately four hours into the experiment, there was a clear sign of $\mathrm{Ti}$ deposition occurring on the surface, as seen in the time-resolved Ti $2 \mathrm{p}$ spectra. In a follow-up experiment presented later in this paper, the first TTIP pulse successfully reached the substrate much faster, in a matter of minutes. The time-resolved data from these initial pulses are shown in Fig. S1 of the supplementary material, together with the duration of each pulse.

A possible explanation for the apparent lack of surface reactions during the initial pulses is that it took some time for the TTIP precursor to react and adsorb on the walls of the gas tubes leading to the cell. Due to the very small amounts of released TTIP vapor and high surface area of the gas tubes, saturation was only reached after a relatively long time. This resulted also in a delay before any Ti signal could be observed on the substrate surface with XPS. The dose of TTIP in each of the pulses is proportional to the duration of the pulse, as the precursor was at a constant temperature of $\sim 50^{\circ} \mathrm{C}$. The effect of the carrier gas flow was also investigated by turning it off during some of the initial pulses, but this appeared to not have a large impact.

We can investigate the appearance of the titanium signal in more detail in Figs. 4(a), 4(d), and 4(g). From these data, it is clear that prior to the pulse, the surface was free from titanium. The Ti $2 p$ core level map further indicates that two clearly distinguishable oxidation states appear during the deposition, with an energy separation of $\sim 1.3 \mathrm{eV}$. These correspond to the $4+$ and $3+$ oxidation states of Ti. During the progression of the TTIP pulse, these two
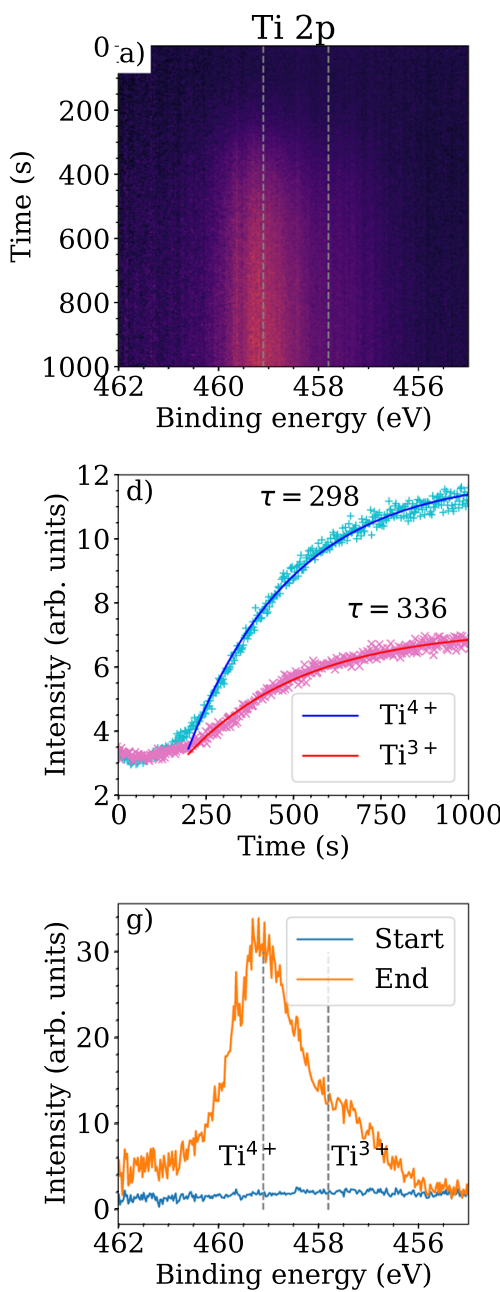
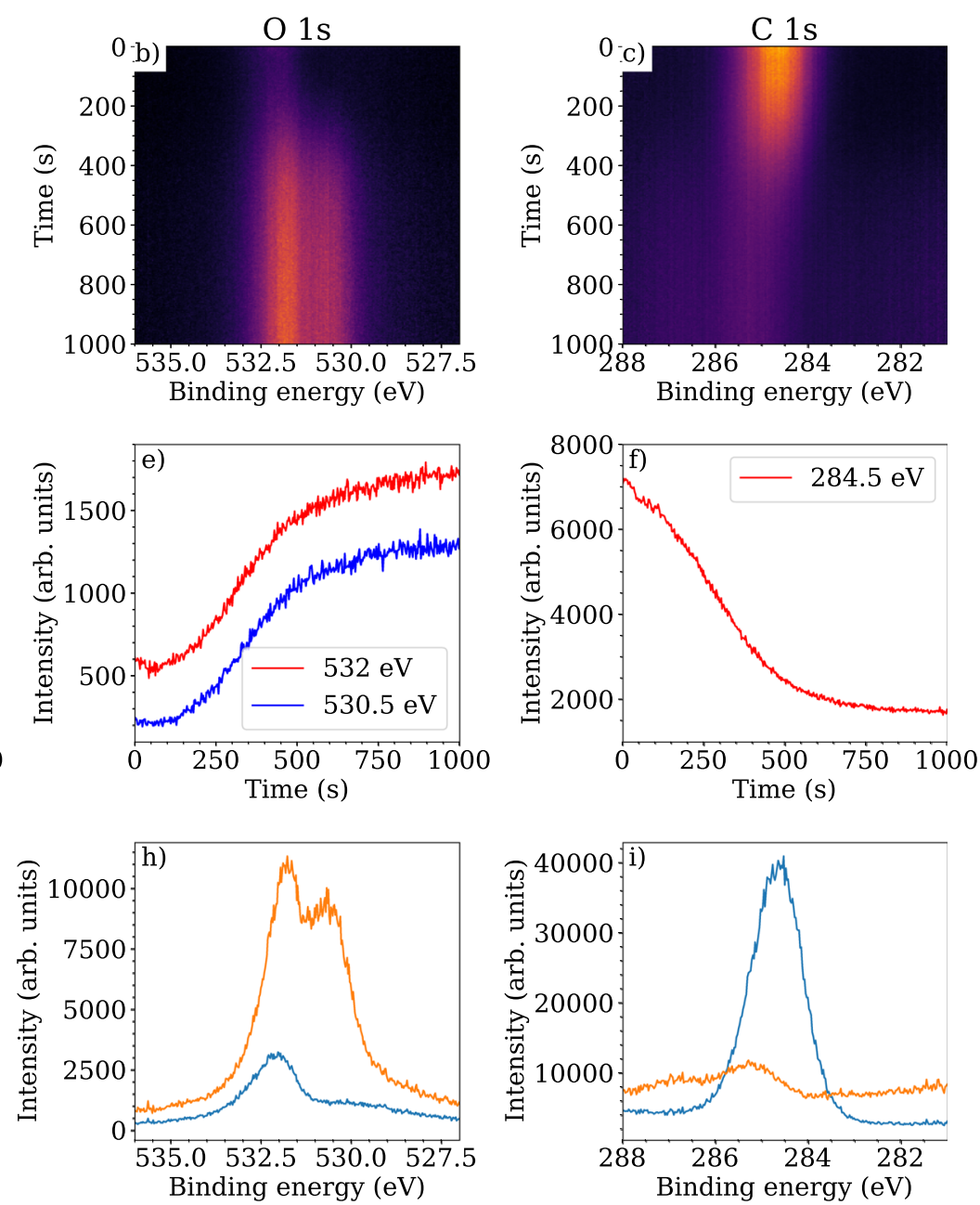

FIG. 4. Time-resolved XPS measurements of (a) Ti $2 p$, (b) 0 1s, and (c) $C$ 1s core levels during the first TTIP half-cycle. All core levels were measured using a photon energy of $640 \mathrm{eV}$. The middle panels show the evolution of the integrated intensities of (d) $\mathrm{Ti}^{3+}$ and $\mathrm{Ti}^{4+}$ features in the Ti $2 \mathrm{p}$ map, (e) evolution of $\mathrm{O} 1 \mathrm{~s}$ intensities as a line scan at 532 and $530.5 \mathrm{eV}$, and (f) C 1s intensity at $284.5 \mathrm{eV}$. The bottom panels show the spectra taken at the beginning and end of the pulse for (g) Ti $2 \mathrm{p}$, (h) $\mathrm{O} 1 \mathrm{~s}$, and (i) C 1s. The total pressure in the cell was $\sim 0.25$ mbar during these measurements. 
components evolve [cf. Fig. 4(d)]. Both components start with zero intensity, but the $4+$ state increases in intensity quicker than the $3+$ one. Toward the end, the intensity ratio of the two components is about 4.5. We can also investigate the timescale of the growth by assuming that the intensity increase follows an exponential format. The intensity increase is plotted in Fig. 4(d) with the fitted exponential function for both components. The exponential function is in the form of $A+B e^{(-t / \tau)}$, where $\tau$ represents a time constant with $A$ and $B$ as fitting constants. For the $4+$ and $3+$ states, the time constants are roughly similar at 298 and $336 \mathrm{~s}$, respectively.

The time-resolved data in the O 1s map [cf. Fig. 4(b)] indicates at least two peaks, which are actually composed of several states. The main features in the $2 \mathrm{D}$ map arise from $\mathrm{SiO}_{2}, \mathrm{TiO}_{2}$, and $\mathrm{Ti}_{2} \mathrm{O}_{3}$ components. The statistics in this map are too poor to conclusively indicate much on the appearance of other features or signals from ligand species on the surface. A notable change in the 2D map is the appearance of the new feature at around $530.5 \mathrm{eV}$ and $250 \mathrm{~s}$, which coincides with the appearance of the Ti signal in the Ti $2 \mathrm{p}$ map. The new feature is therefore a signal from the $\mathrm{TiO}_{2}$ and $\mathrm{Ti}_{2} \mathrm{O}_{3}$ states. The growth of the total intensity in the two most clearly distinguishable binding energy regions is shown as a trend plot in Fig. 4(e), which shows that the they increase with a nearly constant intensity ratio.

Some of the intensity increase in the $\mathrm{O} 1 \mathrm{~s}$ map is indeed due to the newly deposited $\mathrm{TiO}_{2}$ and $\mathrm{Ti}_{2} \mathrm{O}_{3}$ components. However, due to an improper background calibration for the $\mathrm{O} 1 \mathrm{~s}$ map, it is not possible to properly see the disappearance of the $\mathrm{SiO}_{2}$ component and the appearance of the Ti compounds. The snapshot data for the map contains a background detector shape which was not possible to remove in the normalization process for the $\mathrm{O} 1$ s case. Therefore, we cannot conclusively imply anything on the relative intensity ratios of the various $\mathrm{O} 1 \mathrm{~s}$ components. For the $\mathrm{C} 1 \mathrm{~s}$ case, a similar but less severe background normalization issue persists. In the case for the $\mathrm{Ti}$ $2 p$, the detector effect was successfully normalized and the intensity variations are reliable.

Figure 4(c) shows the time-resolved spectra focused on the C 1s core level. Here, we see that the surface was initially largely covered by various carbon species as the sample did not undergo any invacuum cleaning. However, these components are either removed or covered by the TTIP pulse as the total signal intensity in the region significantly decreases during the pulse. Initially, there was a single broad peak at about $284.7 \mathrm{eV}$. This initial peak disappeared during the pulse, revealing two other components at higher binding energies: 285.3 and $286.9 \mathrm{eV}$. These two new peaks most likely originate from the two carbon atoms in different chemical environments in the TTIP molecule (C-O and $\mathrm{C}-\mathrm{H}_{x}$ components).

Figure 5 shows the QMS trend plots of some selected masses during the TTIP pulse. The trends show a large increase for mass 45 , $\mathrm{CH}_{3} \mathrm{CHOH}$, which is a fragment of isopropanol $\left[\left(\mathrm{CH}_{3}\right)_{2} \mathrm{CHOH}\right]$. Isopropanol has been identified as one of the main reaction byproducts released into the gas phase but best seen in the QMS as $\mathrm{CH}_{3} \mathrm{CHOH} .{ }^{65}$ It should be noted that the time correlation between the observations in the QMS trend plot matches very well with the XPS results. The variation in the carrier gas intensity (mass 40) exactly when the other masses start to appear is curious, and the exact reason for it is currently unknown.

After each half-cycle, when there were no further changes on the time-resolved spectra, a full set of swept mode spectra were

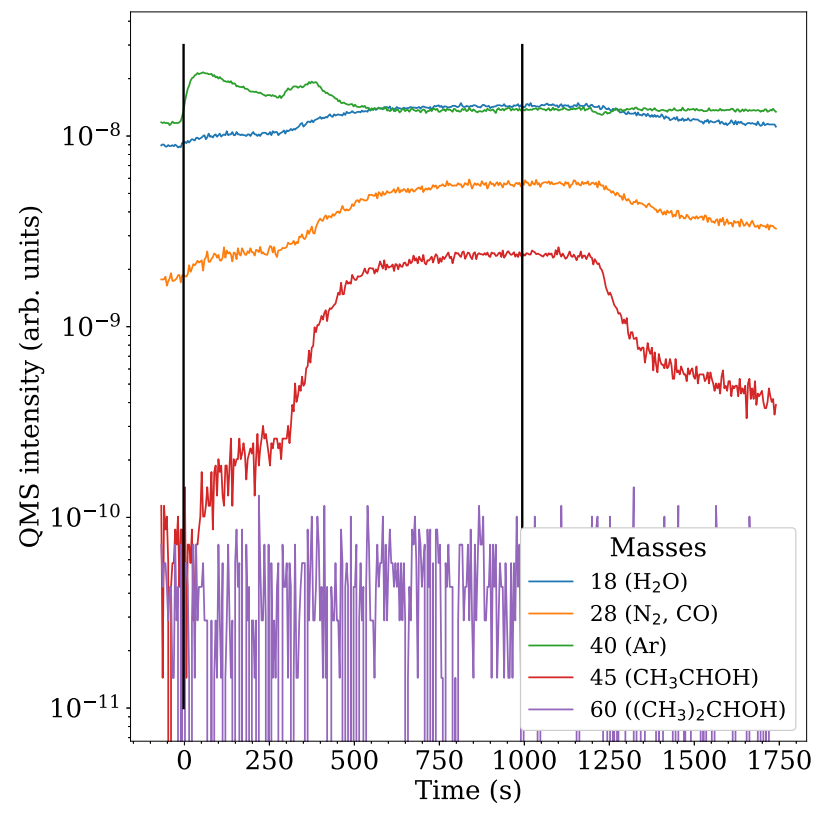

FIG. 5. The QMS trends for specific masses during the first TTIP half-cycle. The vertical bars indicate the time period when the XPS measurement was on-going (i.e., when the data in Fig. 4 were acquired). The timescale has been shifted to match with those in Fig. 4.

measured at different photon energies and settings. These are shown in Fig. 6, which shows the spectra after cycles 0.5, 1.0, 2.5, and 3.0. Obviously, the biggest change is seen before and after the first half-cycle.

Focusing on the Ti $2 \mathrm{p}$ peaks [Fig. 6(a)], we can see that the $\mathrm{Ti}$ $2 p$ peaks are always composed of two components: the $\mathrm{Ti}^{4+}$ and $\mathrm{Ti}^{3+}$ oxidation states centered at about 459.0 and $457.5 \mathrm{eV}$, respectively. The intensity ratio of these compounds changes as more half-cycles are carried out, but the $4+$ peak is always larger. After the first halfcycle, the ratio is about 3.5 , which increases to about 4.6 after the first water cycle (giving more $4+$ contribution). After cycles 2.5 and 3.0 , the ratio is 2.7 and 4.9 , respectively.

In the $\mathrm{O} 1 \mathrm{~s}$ region, a significant change is seen after the initial TTIP pulse, indicating a change from mostly $\mathrm{SiO}_{2}$ surface to a mostly titanium oxide surface. The largest peak has a center at $\sim 530.5 \mathrm{eV}$, indicating $\mathrm{TiO}_{2}$. The peak is asymmetric toward the higher binding energy side, however. The non-stoichiometric titanium oxides would indeed create this, as the $\mathrm{Ti}_{2} \mathrm{O}_{3}$ contribution is often found about $1.3 \mathrm{eV}$ higher than the $\mathrm{TiO}_{2}$ component. By a fitting procedure, we can place another component at $\sim 531.5 \mathrm{eV}$, which is very near where any contribution from $\mathrm{Ti}_{2} \mathrm{O}_{3}$ would appear. The component could also have contribution from the $\mathrm{C}-\mathrm{O}$ bonds, which are known to be in this energy range ${ }^{66}$ and are seen in the corresponding $\mathrm{C} 1 \mathrm{~s}$ spectrum. It is possible that some of the $\mathrm{SiO}_{2}$ contribution is also present here, which would be visible at even higher binding energy as is seen in the spectrum taken before the deposition. The fact that the $\mathrm{SiO}_{2}$ contribution appears to disappear nearly completely even after the first half-cycle is interesting. If we assume that the created surface is $\mathrm{TiO}_{2}$, then the electrons from the $\mathrm{SiO}_{2}$ layer 

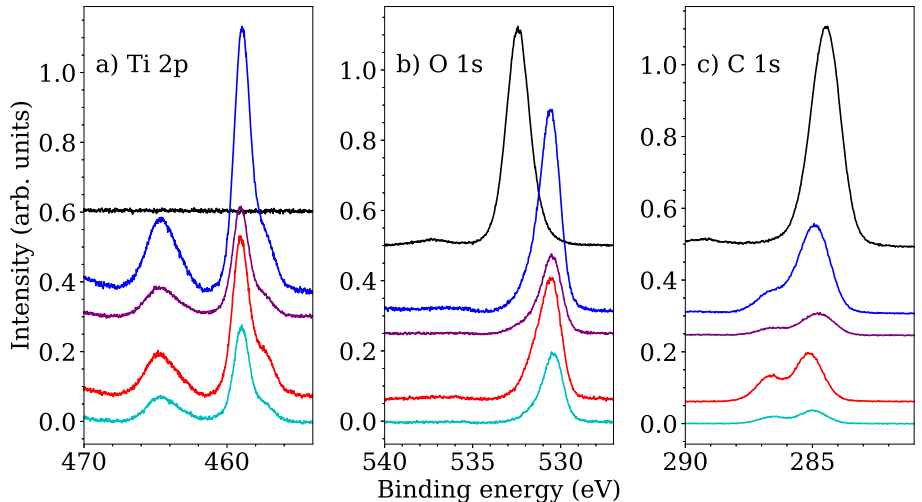

FIG. 6. High-resolution XPS measurements of (a) Ti $2 p$ at $640 \mathrm{eV}$, (b) 0 1s at $640 \mathrm{eV}$, and (c) $\mathrm{C}$ 1s core level at $400 \mathrm{eV}$ before and in between TTIP and $\mathrm{H}_{2} \mathrm{O}$ half-cycles. Black curve represents the core levels before any gas exposure. Red and purple curves are after the first and third TTIP pulses, and blue and teal are after the first and third $\mathrm{H}_{2} \mathrm{O}$ pulses. All spectra have had the background subtracted using a Shirley background shape or a polynomial curve. The spectra are also measured under Ar carrier gas pressure of about $0.1 \mathrm{mbar}$.

would have an inelastic mean free path (IMFP) of $\sim 5 \AA$ A. Below, we will further analyze the unusual thickness of the layer created by the first half-cycle.

The C 1 s spectra show similar results as the other core levels have revealed so far. Initially, there is a large contribution of amorphous surface carbon contamination at a binding energy of $\sim 284.5 \mathrm{eV}$. After the first half-cycle, this peak is greatly reduced in intensity and another component appears at about $287.1 \mathrm{eV}$ (i.e., peak separation of $2.5 \mathrm{eV}$ ). The same effect is also seen in the timeresolved results [Fig. 4(c)], as the large contribution from the surface carbon slowly changes into the two different (new) components. As further cycles are carried out, the peak separation of these two components decreases to about 1.8-1.5 eV. Additionally, the second component at higher binding energies increases in relative intensity after the cycles 1.0, 2.5, and 3.0. Possible origins for these two peaks are the $\mathrm{C}-\mathrm{H}_{x}$ and $\mathrm{C}-\mathrm{O}$ moieties found on the surface before and after the half-cycles. The deposition obviously adds carbon-related compounds on the surface as well in the form of the ligands of the TTIP molecules.

The Si $2 p$ core levels were also measured at each condition (shown in Fig. S2) using a photon energy of $200 \mathrm{eV}$ in order to be surface sensitive. Here, we also see that the bulk Si 2 p signal nearly completely vanishes after already the first half-cycle. The intensity of the $\mathrm{Si}$ oxide peak is also decreased to nearly negligible amounts. Using the typical inelastic mean free path (IMFP) values for $\mathrm{SiO}_{2}$, carbon, or titanium and assuming an electron kinetic energy of $100 \mathrm{eV}$, a simple estimation indicates that the thickness of the layer should be $\sim 15 \AA$ or more in order to completely remove the Si $2 \mathrm{p}$ bulk signal. Since typical growth rates for the TTIP-water process are in the order of $0.5 \AA /$ cycle,${ }^{65,67}$ clearly not all of this thickness originates from the traditional ALD process. Besides the initial Si oxide and a layer of carbonaceous material, it might be possible that there were other processes during the experiment that resulted in a larger-than-expected initial layer thickness. Such processes could be, for example, some CVD mechanism (e.g., due to residual gases in the cell), photofragmentation of the TTIP molecule. Any of these mechanisms, or their sum effect, could have resulted in some degree of uncontrolled growth that creates a thick enough layer to bury the bulk Si signal.

The x-ray beam itself could have a significant effect on the observed ALD growth mechanism. Since the beam is extremely intense, it can cause various effects on the surface, or on the gas phase molecules, during the deposition process itself. The effect of the beam was checked after the first TTIP pulse by moving the sample slightly to measure on a spot which had not been under the x-ray beam during the pulse. The fresh spot had a signal from bulk Si $2 p$, indicating that the $\mathrm{x}$-ray beam itself leads to an increased film thickness on the surface during the initial TTIP pulse. An approximate comparison of the fresh spot also indicates a higher amount of $\mathrm{C} 1 \mathrm{~s}$ signal, while the $\mathrm{O} 1 \mathrm{~s}$ and $\mathrm{Ti} 2 \mathrm{p}$ signals were lower. This would signify that the beam itself helps in forming the titanium oxide layers once the sample is held stationary in the beam for a longer period. However, the ratio of the Ti $2 \mathrm{p}$ oxidation states does not appear to be significantly different.

The first half-cycle measurement was later repeated with the identical starting point as in the first measurement specified above. This time, the time-resolved data were recorded while focusing on the valence band (VB) levels. Other conditions and procedures were the same, but the photon energy was decreased to $50 \mathrm{eV}$ in order to increase the photoionization cross section and therefore signal intensity from the valence band levels. In the measurement, there were no other TTIP pulses prior to the one depicted in the data, and the titanium signal was seen on the surface very soon after opening the valves. The faster transport of TTIP to the sample is probably due to the gas lines being already saturated by it. It should also be noted that the time-resolution in the VB experiment was somewhat reduced when compared to the earlier dataset recorded on the core levels. This change was made due to the increased difficulty with background subtraction in the snapshot mode at the low kinetic energies required for the measurement. A swept mode was therefore used even while recording the time-resolved dataset. The VB dataset was recorded at a time-resolution of about $11 \mathrm{~s}$ instead of the $\sim 2.5 \mathrm{~s}$ used in, e.g., Fig. 4.

Figure 7(a) shows the time-resolved XPS results on the valence band, while the TTIP is introduced to the AP cell. A clear and sudden change in the valence band features is seen already at around $100 \mathrm{~s}$, which coincides in time very close to the point when the TTIP valves were opened. A clearer indication of changes on the surface happens at around $200 \mathrm{~s}$ when the form of the VB begins to change from a $\mathrm{SiO}_{2}$ surface to a more titanium oxide surface. At some selected time positions, line scans have been extracted from the $2 \mathrm{D}$ plot and are shown in Fig. 7(b) to better illustrate the changes to the VB structure. 

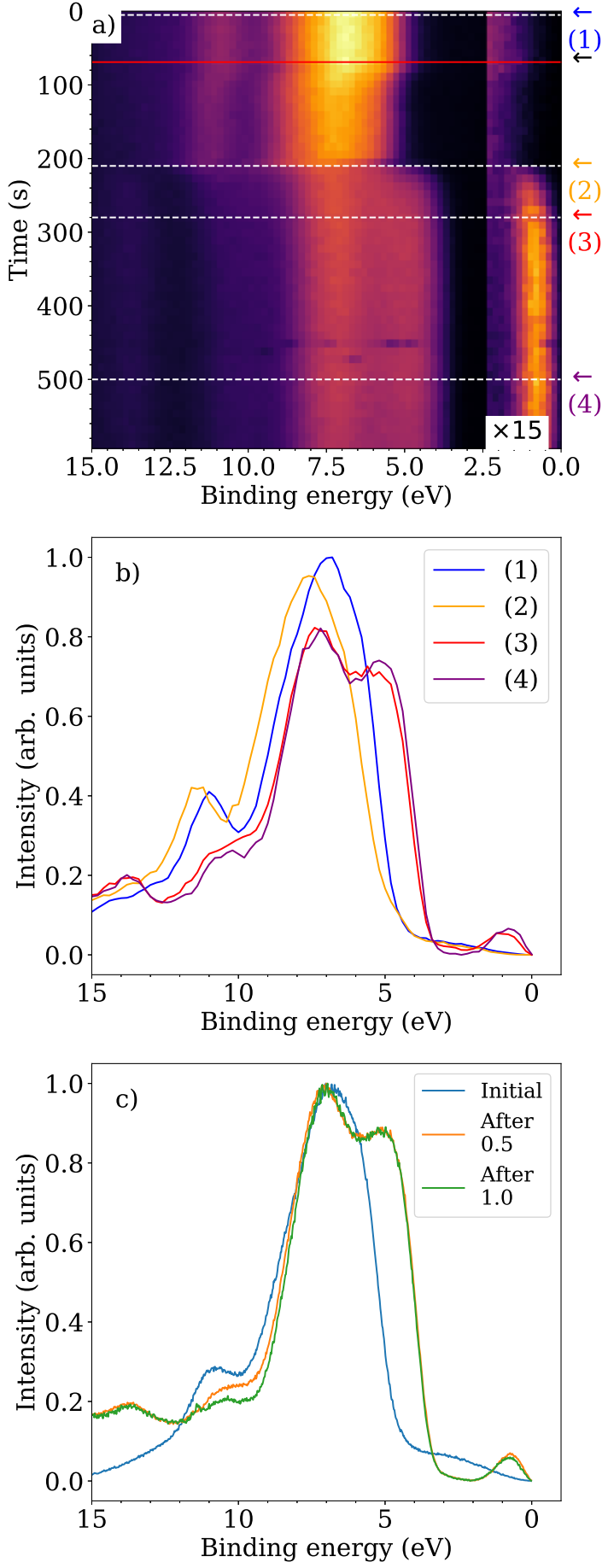

FIG. 7. Time-resolved data from the TTIP pulse (cycle 0.5) while measuring the valence band. The photon energy was $50 \mathrm{eV}$ in all cases and the total pressure in the cell is about 0.25 mbar. The spectra in (b) and (c) have been normalized to produce equal total intensity. Note that the color-scale intensity in the right-hand side of panel (a) has been multiplied by 15 to focus better on the Ti $3 \mathrm{~d}$ states (see text for explanation). The time when the TTIP valve was opened is indicated as a black arrow. The valve remained open during the entire measurement.
In contrast to the earlier measurement focusing on the core levels, here the deposition affects the surface much faster since already at about $300 \mathrm{~s}$ the VB features have ceased changing.

During the sudden shift at $200 \mathrm{~s}$, the whole VB structure moves toward higher binding energy. As the pulse progresses and more TTIP molecules are attached to the surface, the VB maximum, and especially the onset of the $\mathrm{VB}$, is found at lower binding energies (at about $4.5 \mathrm{eV}$ ) than before the pulse (at about $6.0 \mathrm{eV}$ ). An interesting change is also the disappearance of the feature, which is initially seen at $\sim 10.5 \mathrm{eV}$ and then moves toward higher binding energy during the very initial phases of the deposition. Later during the deposition, this feature significantly loses intensity.

At energies close to the Fermi edge, a completely new state appears during the first pulse of the deposition, again at around $200 \mathrm{~s}$ mark. The intensity of this region in Fig. 7(a) has been multiplied by a factor of 15 in order to better visualize changes in it. The peak is located at about $0.8 \mathrm{eV}$ and is associated with the $\mathrm{Ti}$ $3 \mathrm{~d}$ defect states, which indicates formation of a non-stoichiometric oxide $\left(\mathrm{TiO}_{2-x}\right){ }^{68,69}$ Interestingly, the appearance of the $\mathrm{Ti} 3 \mathrm{~d}$ states occurs slightly later in time by about 20-30 s than the initial shift of the VB maximum. Additionally, the Ti $3 \mathrm{~d}$ states initially appear at slightly higher binding energy and gradually shift toward lower energies during the first minute since their initial appearance. A similar shift is also apparent in the whole broad VB structure.

Figure 7(c) shows the valence band spectra measured before the pulses, after the first TTIP half-cycle, and after the first water half-cycle. The intensities in the three spectra have been normalized. Clear differences in the band shape are seen, which is attributed to the grown and incomplete oxide on the surface. Notably, the Ti $3 \mathrm{~d}$ states are clearly visible, and their intensity remains the same even after the water half-cycle. In fact, there are very little changes in the overall shape of the VB between the 0.5 and 1.0 half-cycles. The shape of the valence band initially is in good agreement with that of $\mathrm{SiO}_{2} .{ }^{70}$ After the deposition, the general shape follows that of $\mathrm{TiO}_{2},{ }^{71}$ with some additions from the $\mathrm{Ti}_{2} \mathrm{O}_{3}$ components as well (notably the $3 \mathrm{~d}$ defect states). No gas phase species were detected in the overall valence band shape.

An interesting note is that the $\mathrm{x}$-ray beam appeared to have less of an effect during this VB experiment. The sample was moved after the deposition to check areas that had not been under the direct beam and the surface appeared very similar. This is most likely due to the lower photon energy having less of an effect on the gas phase precursor.

\section{B. Discussion}

The high amount of non-stoichiometric oxide found on the surface after the ALD is a curious effect in this experiment. Similar results have been reported previously, although an extensive reasoning has not been elucidated. In one case, in the work of Hannula et al., ${ }^{72}$ a clear $\mathrm{Ti}^{3+}$ signal was observed on the as-deposited surface which was created using tetrakis(dimethylamido)-Ti(IV) (TDMAT) and water. In their case, the surface was cleaned off organic contaminants as well as other metal containing impurities. The authors report on some carbon impurities, but it appears to be negligible with respect to our surface here. However, since TDMAT is known to decompose easily, the appearance of the lower oxidation 
state components could simply be explained by different reactions involving the precursor itself.

In another case, in the work of Bronneberg et al., ${ }^{73}$ where the $\mathrm{TiO}_{2}$ ALD was done using $\mathrm{TiCl}_{4}$, the $3+$ oxidation state was also observed at relatively high quantities after the first half-cycle. The Si substrate in their case was used as-received, with very little cleaning. Their interpretation is that the sub-stoichiometric layer is formed near the $\mathrm{SiO}_{2}$ interface. According to them, the mechanisms that create this could involve nucleation differences on the first monolayers or possible oxygen diffusion through the native oxide.

In our experiment, the Si surface was introduced to the ALD cell with no cleaning at all, and it, therefore, had a large amount of carbonaceous compounds on the surface. Whether this plays a role in the initial steps of the first half-cycle is curious, but it is clearly the biggest difference in the initial state of the surface with respect to cases that report a full $\mathrm{TiO}_{2}$ surface. On the other hand, work by Lee et al..$^{30}$ also demonstrates that even if the Si substrate is thoroughly cleaned and $\mathrm{OH}$-terminated using $\mathrm{H}_{2} \mathrm{O}$, it is still possible to create a $\mathrm{Ti}_{2} \mathrm{O}_{3}$ surface. In their case, after the first TTIP pulse, the surface was dominated by the $\mathrm{Ti}^{3+}$ component and the $4+$ component became the largest one only after the second TTIP pulse (cycle 2.0).

It is known that the simplified first half-cycle reaction according to the ligand-exchange mechanism ${ }^{65}$ involves an interaction between the TTIP molecule and about two surface hydroxyl groups. ${ }^{8}$ In our results, the reaction mechanism clearly deviates from the simple ligand-exchange route, since it should not involve any oxidation or reduction reactions. In addition, in our case, there were no clear signs of hydroxyl species on the initial surface. Most of the reported cases for the deposition of $\mathrm{TiO}_{2}$ on $\mathrm{Si}$, which have used XPS as the analysis tool, nearly always start with a clean and oxidized (or $\mathrm{OH}$ terminated) Si surface. It could therefore be that not so much is known about the reactions involving a more complicated initial state of the surface, such as in our experiment. The preliminary nature of this experiment and the larger-than-expected effect of the x-ray beam, however, only allow us to make qualitative assumptions on the exact reaction mechanism in this case.

\section{CONCLUSIONS}

A new sample environment dedicated for studying ALD using ambient pressure $\mathrm{x}$-ray photoelectron spectroscopy is described. This experimental setup is named "the ALD cell" and has been designed and constructed based on the APXPS principles of a cell-incell technique with strong input from the ALD reactor design. The cell can be pressurized up to 20 mbar with substrate heating capabilities up to $400^{\circ} \mathrm{C}$ while allowing operando XPS measurements. The cell consists of individual gas inlet lines for two precursors and a dedicated pumping line to evacuate the unreacted gaseous precursor as well as to evacuate the cell into vacuum conditions. The cell is installed at the SPECIES beamline, which provides a unique place for APXPS experiments with a broad $\mathrm{x}$-ray energy range from 30 to $1500 \mathrm{eV}$. Additionally, the cell is connected to a quadrupole mass spectrometer, allowing us to correlate observed gas phase species with surface features seen with XPS. It is expected that the results obtained with the cell can be of much interest in deconvoluting the chemical processes and details of surface adsorbates during the deposition process.
To showcase some results, we have shown the investigation on the deposition of titanium dioxide on top of the natively oxidized silicon substrate. Time-resolved ambient pressure XP spectra taken during the deposition reveal how the different oxidation states of $\mathrm{Ti}$ evolve over the course of the first half-cycle. Additionally, a small amount of non-stoichiometric titanium oxide is observed in the deposited film. The exact reason for the reduced titanium oxide surface is left unknown, but tentative reasons can be attributed to a high amount of organic carbon on the surface. Our results reveal a somewhat more complicated picture for the first steps of the growth than anticipated. Clearly, several processes are on-going on the surface during the initial stages of the precursor exposure. The employed technique of real-time XPS acquisition allows us to observe these effects which otherwise would be left unknown. In order to gain more information and properly elucidate the reaction mechanisms, more detailed in situ/operando studies would be needed. This work also highlights the need to carefully observe effects due to the synchrotron beam itself. In this work, the beam unfortunately caused a larger than anticipated thickness of the first layer. Such problems can be avoided in future studies with careful planning of the measurements, for example, by constantly moving the sample so that the contribution from intense $\mathrm{x}$ rays on the layer growth is minimized.

While this work has produced some new information, several questions still remain. Most notably, the effect of the initial Si surface quality which plays a very large role in the growth of the first layer requires further experimentation. This is the first time to our knowledge that valence bands have been measured with time-resolution during the deposition, which when combined with the time-resolved core level XPS can provide a unique source of information on the exact nature of the deposition. In addition, this study also highlights the need for knowing details of the interactions between $\mathrm{x}$ rays and gas phase ALD precursors, since they can strongly influence the deposition. Clearly, it is very important to avoid x-ray beam induced effects by either reducing the photon flux significantly (with synchrotron measurements) or by continuously moving the sample during deposition. Apart from a few studies, ${ }^{74,75}$ very little is known, for example, on the gas phase electronic structure or the molecular photofragmentation after x-ray ionization. On the other hand, some measurements might even take advantage of the beam induced effects, in a similar way that is done using, e.g., electron beam-induced deposition (EBID). ${ }^{7}$

\section{SUPPLEMENTARY MATERIAL}

See the supplementary material for the time-resolved snapshot data on all TTIP pulses prior to those depicted in Fig. 4 and for the post-deposition spectra of the Si 2 p core level.

\section{ACKNOWLEDGMENTS}

The ALD cell is a result of collaboration between the University of Helsinki (Finland) and the MAX IV Laboratory and funded by the Faculty of Science, University of Helsinki and Academy of Finland (Grant No. 295696) under the operations collaboration agreement between Finland (FIMAX consortium) and the MAX IV Laboratory. Research conducted at MAX IV, a Swedish national user facility, is supported by the Swedish Research Council under 
Contract No. 2018-07152, the Swedish Governmental Agency for Innovation Systems under Contract No. 2018-04969, and Formas under Contract No. 2019-02496. M.P. acknowledges funding from the Academy of Finland by the profiling action on Matter and Materials (Grant No. 318913). M.R. acknowledges funding from the Academy of Finland (Grant No. 309552). J.S. acknowledges funding from Vetenskapsrådet (Swedish Research Council) under Grant No. 2017-03871. The authors thank the MAX IV staff and especially Mikko-Heikki Mikkelä and Jörgen Hellborg for help in the design, construction, and testing of the ALD cell.

\section{AUTHOR DECLARATIONS}

\section{Conflict of Interest}

The authors have no conflicts to disclose.

\section{DATA AVAILABILITY}

The data that support the findings of this study are available from the corresponding author upon reasonable request.

\section{REFERENCES}

${ }^{1}$ T. Suntola and J. Hyvärinen, “Atomic layer epitaxy," Annu. Rev. Mater. Sci. 15, 177-195 (1985).

${ }^{2} \mathrm{~K}$. Knapas and M. Ritala, "In situ studies on reaction mechanisms in atomic layer deposition," Crit. Rev. Solid State Mater. Sci. 38, 167-202 (2013).

${ }^{3} \mathrm{~F}$. Zaera, "Mechanisms of surface reactions in thin solid film chemical deposition processes," Coord. Chem. Rev. 257, 3177-3191 (2013).

${ }^{4}$ N. E. Richey, C. de Paula, and S. F. Bent, "Understanding chemical and physical mechanisms in atomic layer deposition," J. Chem. Phys. 152, 040902 (2020).

${ }^{5}$ W. M. M. Kessels and M. Putkonen, "Advanced process technologies: Plasma, direct-write, atmospheric pressure, and roll-to-roll ALD," MRS Bull. 36, 907-913 (2011).

${ }^{6}$ J. W. Elam, M. D. Groner, and S. M. George, "Viscous flow reactor with quartz crystal microbalance for thin film growth by atomic layer deposition," Rev. Sci. Instrum. 73, 2981-2987 (2002).

${ }^{7}$ M. D. Groner, F. H. Fabreguette, J. W. Elam, and S. M. George, "Lowtemperature $\mathrm{Al}_{2} \mathrm{O}_{3}$ atomic layer deposition," Chem. Mater. 16, 639-645 (2004).

${ }^{8} \mathrm{~A}$. Rahtu, K. Kukli, and M. Ritala, "In situ mass spectrometry study on atomic layer deposition from metal ( $\mathrm{Ti}, \mathrm{Ta}$, and $\mathrm{Nb}$ ) ethoxides and water," Chem. Mater. 13, 817-823 (2001).

${ }^{9}$ T. Aaltonen, M. Ritala, K. Arstila, J. Keinonen, and M. Leskelä, "Atomic layer deposition of ruthenium thin films from $\mathrm{Ru}(\mathrm{thd})_{3}$ and oxygen," Chem. Vap. Deposition 10, 215-219 (2004).

${ }^{10}$ E. Langereis, S. B. S. Heil, H. C. M. Knoops, W. Keuning, M. C. M. Van de Sanden, and W. M. M. Kessels, "In situ spectroscopic ellipsometry as a versatile tool for studying atomic layer deposition," J. Phys. D: Appl. Phys. 42, 073001 (2009).

${ }^{11}$ K. Cao, Q. Hu, J. Cai, M. Gong, J. Yang, B. Shan, and R. Chen, "Development of a scanning probe microscopy integrated atomic layer deposition system for in situ successive monitoring of thin film growth," Rev. Sci. Instrum. 89, 123702 (2018). ${ }^{12}$ J. D. Ferguson, E. R. Smith, A. W. Weimer, and S. M. George, "ALD of $\mathrm{SiO}_{2}$ at room temperature using TEOS and $\mathrm{H}_{2} \mathrm{O}$ with $\mathrm{NH}_{3}$ as the catalyst," J. Electrochem. Soc. 151, G528 (2004).

${ }^{13}$ D. N. Goldstein, J. A. McCormick, and S. M. George, " $\mathrm{Al}_{2} \mathrm{O}_{3}$ atomic layer deposition with trimethylaluminum and ozone studied by in situ transmission FTIR spectroscopy and quadrupole mass spectrometry," J. Phys. Chem. C 112, 19530-19539 (2008)

${ }^{14}$ S. K. Park, R. Kanjolia, J. Anthis, R. Odedra, N. Boag, L. Wielunski, and Y. J. Chabal, "Atomic layer deposition of $\mathrm{Ru} / \mathrm{RuO}_{2}$ thin films studied by in situ infrared spectroscopy,” Chem. Mater. 22, 4867-4878 (2010).
${ }^{15}$ B. A. Sperling, J. Hoang, W. A. Kimes, J. E. Maslar, K. L. Steffens, and N. V. Nguyen, "Time-resolved surface infrared spectroscopy during atomic layer deposition of $\mathrm{TiO}_{2}$ using tetrakis(dimethylamido)titanium and water," J. Vac. Sci. Technol. A 32, 031513 (2014).

${ }^{16}$ L. Keskiväli, M. Putkonen, E. Puhakka, E. Kenttä, J. Kint, R. K. Ramachandran, C. Detavernier, and P. Simell, "Molecular layer deposition using ring-opening reactions: Molecular modeling of the film growth and the effects of hydrogen peroxide," ACS Omega 3, 7141-7149 (2018).

${ }^{17}$ M. Kobayashi, P. T. Chen, Y. Sun, N. Goel, P. Majhi, M. Garner, W. Tsai, P. Pianetta, and Y. Nishi, "Synchrotron radiation photoemission spectroscopic study of band offsets and interface self-cleaning by atomic layer deposited $\mathrm{HfO}_{2}$ on $\mathrm{In}_{0.53} \mathrm{Ga}_{0.47} \mathrm{As}$ and $\mathrm{In}_{0.52} \mathrm{Al}_{0.48}$ As," Appl. Phys. Lett. 93, 182103 (2008).

${ }^{18} \mathrm{M}$. Tallarida, K. Karavaev, and D. Schmeisser, "The initial atomic layer deposition of $\mathrm{HfO}_{2} / \mathrm{Si}(001)$ as followed in situ by synchrotron radiation photoelectron spectroscopy," J. Appl. Phys. 104, 064116 (2008).

${ }^{19} \mathrm{M}$. Tallarida, K. Karavaev, and D. Schmeisser, " $\mathrm{HfO}_{2} / \mathrm{Si}$ interface formation in atomic layer deposition films: An in situ investigation," J. Vac. Sci. Technol. B 27, 300-304 (2009).

${ }^{20} \mathrm{M}$. Tallarida and D. Schmeisser, "In situ ALD experiments with synchrotron radiation photoelectron spectroscopy," Semicond. Sci. Technol. 27, 074010 (2012).

${ }^{21}$ K. Kolanek, M. Tallarida, M. Michling, and D. Schmeisser, "In situ study of the atomic layer deposition of $\mathrm{HfO}_{2}$ on Si," J. Vac. Sci. Technol. A 30, $01 \mathrm{~A} 143$ (2012).

${ }^{22}$ R. Methaapanon, S. M. Geyer, C. Hagglund, P. A. Pianetta, and S. F. Bent, "Portable atomic layer deposition reactor for in situ synchrotron photoemission studies," Rev. Sci. Instrum. 84, 015104 (2013).

${ }^{23}$ S. M. Geyer, R. Methaapanon, B. Shong, P. A. Pianetta, and S. F. Bent, "In vacuo photoemission studies of platinum atomic layer deposition using synchrotron radiation," J. Phys. Chem. Lett. 4, 176-179 (2013).

${ }^{24}$ K. Devloo-Casier, K. F. Ludwig, C. Detavernier, and J. Dendooven, "In situ synchrotron based x-ray techniques as monitoring tools for atomic layer deposition," J. Vac. Sci. Technol. A 32, 010801 (2014).

${ }^{25}$ Y. Hwang, K. Heo, C. H. Chang, M. K. Joo, and M. Ree, "Synchrotron X-ray reflectivity study of high dielectric constant alumina thin films prepared by atomic layer deposition," Thin Solid Films 510, 159-163 (2006).

${ }^{26}$ D. D. Fong, J. A. Eastman, S. K. Kim, T. T. Fister, M. J. Highland, P. M. Baldo, and P. H. Fuoss, "In situ synchrotron $\mathrm{x}$-ray characterization of $\mathrm{ZnO}$ atomic layer deposition," Appl. Phys. Lett. 97, 191904 (2010).

${ }^{27}$ K. Devloo-Casier, J. Dendooven, K. F. Ludwig, G. Lekens, J. D’Haen, and C. Detavernier, "In situ synchrotron based x-ray fluorescence and scattering measurements during atomic layer deposition: Initial growth of $\mathrm{HfO}_{2}$ on $\mathrm{Si}$ and Ge substrates," Appl. Phys. Lett. 98, 231905 (2011).

${ }^{28}$ Y. J. Park, D. R. Lee, H. H. Lee, H.-B.-R. Lee, H. Kim, G.-C. Park, S.-W. Rhee, and S. Baik, "In-situ synchrotron X-ray scattering study of thin film growth by atomic layer deposition," J. Nanosci. Nanotechnol. 11, 1577-1580 (2011).

${ }^{29}$ Y. J. Park, D. R. Lee, and S. Baik, "Synchrotron X-ray reflectivity for characterization of the initial ALD growth of TaN," J. Korean Phys. Soc. 59, 458-460 (2011).

${ }^{30}$ S. Y. Lee, C. Jeon, S. H. Kim, Y. Kim, W. Jung, K.-S. An, and C.-Y. Park, "In-situ $\mathrm{X}$-ray photoemission spectroscopy study of atomic layer deposition of $\mathrm{TiO}_{2}$ on silicon substrate," Jpn. J. Appl. Phys., Part 1 51, 031102 (2012).

${ }^{31}$ J. A. Klug, M. S. Weimer, J. D. Emery, A. Yanguas-Gil, S. Seifert, C. M. Schlepütz, A. B. F. Martinson, J. W. Elam, A. S. Hock, and T. Proslier, "A modular reactor design for in situ synchrotron $\mathrm{x}$-ray investigation of atomic layer deposition processes," Rev. Sci. Instrum. 86, 113901 (2015).

${ }^{32}$ S.-J. Park, W.-H. Kim, W. J. Maeng, Y. S. Yang, C. G. Park, H. Kim, K.-N. Lee, S.-W. Jung, and W. K. Seong, "Effect oxygen exposure on the quality of atomic layer deposition of ruthenium from bis(cyclopentadienyl)ruthenium and oxygen," Thin Solid Films 516, 7345-7349 (2008).

${ }^{33}$ R. Methaapanon, S. M. Geyer, S. Brennan, and S. F. Bent, "Size dependent effects in nucleation of Ru and Ru oxide thin films by atomic layer deposition measured by synchrotron radiation x-ray diffraction," Chem. Mater. 25, 3458-3463 (2013). ${ }^{34}$ J. Dendooven, S. Pulinthanathu Sree, K. De Keyser, D. Deduytsche, J. A. Martens, K. F. Ludwig, and C. Detavernier, "In situ x-ray fluorescence measurements during atomic layer deposition: Nucleation and growth of $\mathrm{TiO}_{2}$ on planar substrates and in nanoporous films," J. Phys. Chem. C 115, 6605-6610 (2011). 
${ }^{35}$ E. Levrau, K. Devloo-Casier, J. Dendooven, K. F. Ludwig, P. Verdonck, J. Meersschaut, M. R. Baklanov, and C. Detavernier, "Atomic layer deposition of $\mathrm{TiO}_{2}$ on surface modified nanoporous low-k films," Langmuir 29, 12284-12289 (2013).

${ }^{36}$ J. Dendooven, K. Devloo-Casier, M. Ide, K. Grandfield, K. F. Ludwig, S. Bals, P. Van Der Voort, and C. Detavernier, "In situ study of ALD processes using synchrotron-based x-ray fluorescence and scattering techniques," ECS Trans. 50, 35 (2013).

${ }^{37}$ J. Dendooven, E. Solano, M. M. Minjauw, K. Van de Kerckhove, A. Coati, E. Fonda, G. Portale, Y. Garreau, and C. Detavernier, "Mobile setup for synchrotron based in situ characterization during thermal and plasma-enhanced atomic layer deposition," Rev. Sci. Instrum. 87, 113905 (2016).

${ }^{38}$ W. Setthapun, W. D. Williams, S. M. Kim, H. Feng, J. W. Elam, F. A. Rabuffetti, K. R. Poeppelmeier, P. C. Stair, E. A. Stach, F. H. Ribeiro et al., "Genesis and evolution of surface species during Pt atomic layer deposition on oxide supports characterized by in situ XAFS analysis and water-gas shift reaction," J. Phys. Chem. C 114, 9758-9771 (2010).

${ }^{39}$ X. Qu, D. Yan, R. Li, J. Cen, C. Zhou, W. Zhang, D. Lu, K. Attenkofer, D. J. Stacchiola, M. S. Hybertsen, E. Stavitski, and M. Liu, "Resolving the evolution of atomic layer-deposited thin-film growth by continuous in situ $\mathrm{x}$-ray absorption spectroscopy," Chem. Mater. 33, 1740-1751 (2021).

${ }^{40} \mathrm{~J}$. Schnadt, J. Knudsen, and N. Johansson, "Present and new frontiers in materials research by ambient pressure x-ray photoelectron spectroscopy," J. Phys.: Condens. Matter 32, 413003 (2020).

${ }^{41}$ P. Amann, D. Degerman, M.-T. Lee, J. D. Alexander, M. Shipilin, H.-Y. Wang, F. Cavalca, M. Weston, J. Gladh, M. Blom et al., "A high-pressure x-ray photoelectron spectroscopy instrument for studies of industrially relevant catalytic reactions at pressures of several bars," Rev. Sci. Instrum. 90, 103102 (2019).

${ }^{42}$ S. Chaudhary, A. R. Head, R. Sánchez-de-Armas, H. Tissot, G. Olivieri, F. Bournel, L. Montelius, L. Ye, F. Rochet, J.-J. Gallet et al., "Real-time study of CVD growth of silicon oxide on rutile $\mathrm{TiO}_{2}(110)$ using tetraethyl orthosilicate," J. Phys. Chem. C 119, 19149-19161 (2015).

${ }^{43}$ A. R. Head, S. Chaudhary, G. Olivieri, F. Bournel, J. N. Andersen, F. Rochet, J.-J. Gallet, and J. Schnadt, "Near ambient pressure x-ray photoelectron spectroscopy study of the atomic layer deposition of $\mathrm{TiO}_{2}$ on $\mathrm{RuO}_{2}(110)$," J. Phys. Chem. C 120, 243-251 (2016).

${ }^{44}$ R. Timm, A. R. Head, S. Yngman, J. V. Knutsson, M. Hjort, S. R. McKibbin, A. Troian, O. Persson, S. Urpelainen, J. Knudsen, J. Schnadt, and A. Mikkelsen, "Self-cleaning and surface chemical reactions during hafnium dioxide atomic layer deposition on indium arsenide," Nat. Commun. 9, 1412 (2018).

${ }^{45}$ A. R. Head, N. Johansson, Y. Niu, O. Snezhkova, S. Chaudhary, J. Schnadt, H. Bluhm, C. Chen, J. Avila, and M.-C. Asensio, "In situ characterization of the deposition of anatase $\mathrm{TiO}_{2}$ on rutile $\mathrm{TiO}_{2}(110)$," J. Vac. Sci. Technol. A 36, $02 \mathrm{D} 405$ (2018).

${ }^{46}$ J. Schnadt, J. Knudsen, and A. Shavorskiy, "Thin-film growth and oxidation of surfaces under relevant pressure conditions," in Encyclopedia of Interfacial Chemistry, edited by K. Wandelt (Elsevier, Oxford, 2018), pp. 699-710.

${ }^{47}$ R. H. Temperton, A. Gibson, and J. N. O'Shea, "In situ XPS analysis of the atomic layer deposition of aluminium oxide on titanium dioxide," Phys. Chem. Chem. Phys. 21, 1393-1398 (2019).

${ }^{48}$ G. D’Acunto, A. Troian, E. Kokkonen, F. Rehman, Y.-P. Liu, S. Yngman, Z. Yong, S. R. McKibbin, T. Gallo, E. Lind et al., "Atomic layer deposition of hafnium oxide on InAs: Insight from time-resolved in situ studies," ACS Appl. Electron. Mater. 2, 3915-3922 (2020).

${ }^{49}$ E. A. Redekop, N. Johansson, E. Kokkonen, S. Urpelainen, F. Lopes da Silva, M. Kaipio, H.-E. Nieminen, F. Rehman, V. Miikkulainen, M. Ritala et al., "Synchronizing gas injections and time-resolved data acquisition for perturbation-enhanced APXPS experiments," Rev. Sci. Instrum. 92, 044101 (2021).

${ }^{50}$ S. M. George, "Atomic layer deposition: An overview," Chem. Rev. 110, 111-131 (2010).

${ }^{51}$ G. N. Parsons, S. M. George, and M. Knez, "Progress and future directions for atomic layer deposition and ALD-based chemistry," MRS Bull. 36, 865-871 (2011).
${ }^{52} \mathrm{P}$. Shayesteh, "Atomic layer deposition and immobilised molecular catalysts studied by in and ex situ electron spectroscopy," Ph.D. thesis, Lund University, Faculty of Science, Department of Physics, 2019.

${ }^{53}$ S. Urpelainen, C. Såthe, W. Grizolli, M. Agåker, A. R. Head, M. Andersson, S.-W. Huang, B. N. Jensen, E. Wallén, H. Tarawneh, R. Sankari, R. Nyholm, M. Lindberg, P. Sjöblom, N. Johansson, B. N. Reinecke, M. A. Arman, L. R. Merte, J. Knudsen, J. Schnadt, J. N. Andersen, and F. Hennies, "The SPECIES beamline at the MAX IV laboratory: A facility for soft X-ray RIXS and APXPS," J. Synchrotron Radiat. 24, 344-353 (2017).

${ }^{54}$ E. Kokkonen, F. Lopes da Silva, M.-H. Mikkelã, N. Johansson, S.-W. Huang, J.-M. Lee, M. Andersson, A. Bartalesi, B. N. Reinecke, K. Handrup, H. Tarawneh, R. Sankari, J. Knudsen, J. Schnadt, C. Såthe, and S. Urpelainen, "Upgrade of the SPECIES beamline at the MAX IV laboratory," J. Synchrotron Radiat. 28, 588-601 (2021).

${ }^{55} \mathrm{M}$. Leskelä and M. Ritala, "Atomic layer deposition chemistry: Recent developments and future challenges,” Angew. Chem., Int. Ed. 42, 5548-5554 (2003).

${ }^{56}$ K.-E. Elers, T. Blomberg, M. Peussa, B. Aitchison, S. Haukka, and S. Marcus, "Film uniformity in atomic layer deposition," Chem. Vap. Deposition 12, 13-24 (2006).

${ }^{57}$ H. C. M. Knoops, S. E. Potts, A. A. Bol, and W. M. M. Kessels, "27-Atomic layer deposition," in Handbook of Crystal Growth, 2nd ed., edited by T. F. Kuech (North-Holland, Boston, 2015), pp. 1101-1134.

${ }^{58} \mathrm{D}$. Pan, T. Li, T. Chien Jen, and C. Yuan, "Numerical modeling of carrier gas flow in atomic layer deposition vacuum reactor: A comparative study of lattice Boltzmann models," J. Vac. Sci. Technol. A 32, 01 A110 (2014).

${ }^{59}$ F. F. Tao, "Operando studies of catalyst surfaces during catalysis and under reaction conditions: Ambient pressure $\mathrm{x}$-ray photoelectron spectroscopy with a flow-cell reactor," Chem CatChem 4, 583-590 (2012).

${ }^{60}$ J. Schnadt, J. Knudsen, J. N. Andersen, H. Siegbahn, A. Pietzsch, F. Hennies, N. Johansson, N. Mårtensson, G. Öhrwall, S. Bahr, S. Mähl, and O. Schaff, "The new ambient-pressure X-ray photoelectron spectroscopy instrument at MAX-lab," J. Synchrotron Radiat. 19, 701-704 (2012).

${ }^{61}$ D. E. Starr, Z. Liu, M. Hävecker, A. Knop-Gericke, and H. Bluhm, "Investigation of solid/vapor interfaces using ambient pressure X-ray photoelectron spectroscopy," Chem. Soc. Rev. 42, 5833-5857 (2013).

${ }^{62} \mathrm{~J}$. Knudsen, J. N. Andersen, and J. Schnadt, "A versatile instrument for ambient pressure x-ray photoelectron spectroscopy: The Lund cell approach," Surf. Sci. 646, 160-169 (2016).

${ }^{63}$ S. Nadzirah, S. C. B. Gopinath, N. A. Parmin, A. A. Hamzah, M. A. Mohamed, E. Y. Chang, and C. F. Dee, "State-of-the-art on functional titanium dioxide-integrated nano-hybrids in electrical biosensors," Crit. Rev. Anal. Chem. (published online 2020).

${ }^{64}$ J.-P. Niemelä, G. Marin, and M. Karppinen, "Titanium dioxide thin films by atomic layer deposition: A review," Semicond. Sci. Technol. 32, 093005 (2017).

${ }^{65} \mathrm{~A}$. Rahtu and M. Ritala, "Reaction mechanism studies on titanium isopropoxide-water atomic layer deposition process," Chem. Vap. Deposition $\mathbf{8}$, 21-28 (2002).

${ }^{66} \mathrm{E}$. McCafferty and J. P. Wightman, "Determination of the concentration of surface hydroxyl groups on metal oxide films by a quantitative XPS method," Surf. Interface Anal. 26, 549-564 (1998).

${ }^{67}$ J. Aarik, A. Aidla, T. Uustare, M. Ritala, and M. Leskelä, “Titanium isopropoxide as a precursor for atomic layer deposition: Characterization of titanium dioxide growth process," Appl. Surf. Sci. 161, 385-395 (2000).

${ }^{68}$ A. G. Thomas, W. R. Flavell, A. R. Kumarasinghe, A. K. Mallick, D. Tsoutsou, G. C. Smith, R. Stockbauer, S. Patel, M. Grätzel, and R. Hengerer, "Resonant photoemission of anatase $\mathrm{TiO}_{2}$ (101) and (001) single crystals," Phys. Rev. B 67, 035110 (2003).

${ }^{69}$ P. Le Fèvre, J. Danger, H. Magnan, D. Chandesris, J. Jupille, S. Bourgeois, M.-A. Arrio, R. Gotter, A. Verdini, and A. Morgante, "Stoichiometry-related Auger lineshapes in titanium oxides: Influence of valence-band profile and of Coster-Kronig processes," Phys. Rev. B 69, 155421 (2004).

${ }^{70}$ A. Palma and A. Alavi, "An ab initio study of titanium tetra-iso-propoxide (TTIP) adsorption mechanism on a Si(100) surface," Comput. Mater. Sci. 33, 244-249 (2005). 
${ }^{71}$ L. Fleming, C. C. Fulton, G. Lucovsky, J. E. Rowe, M. D. Ulrich, and J. Lüning, "Local bonding analysis of the valence and conduction band features of $\mathrm{TiO}_{2}$," J. Appl. Phys. 102, 033707 (2007).

${ }^{72}$ M. Hannula, H. Ali-Löytty, K. Lahtonen, E. Sarlin, J. Saari, and M. Valden, "Improved stability of atomic layer deposited amorphous $\mathrm{TiO}_{2}$ photoelectrode coatings by thermally induced oxygen defects," Chem. Mater. 30, 1199-1208 (2018).

${ }^{73}$ A. C. Bronneberg, C. Höhn, and R. Van De Krol, "Probing the interfacial chemistry of ultrathin ALD-grown $\mathrm{TiO}_{2}$ films: An in-line XPS study,” J. Phys. Chem. C 121, 5531-5538 (2017).
${ }^{74}$ I. Novak, B. Kovač, and M. Jokić, "Electronic structure of two precursors for nanofabrication: $\left[(\mathrm{CH} 3)_{3} \mathrm{CN}\right]_{2} \mathrm{~W}\left[\mathrm{~N}\left(\mathrm{CH}_{3}\right)_{2}\right]_{2}$ and $\mathrm{Ti}\left(\mathrm{NMe}_{2}\right)_{2}\left(\mathrm{NEt}_{2}\right)_{2}$," J. Phys. Chem. A 118, 5636-5641 (2014).

${ }^{75}$ P. Shayesteh, R. Tsyshevsky, S. Urpelainen, F. Rochet, F. Bournel, J.-J. Gallet, M. M. Kuklja, J. Schnadt, and A. R. Head, "Experimental and theoretical gas phase electronic structure study of tetrakis(dimethylamino) complexes of Ti(IV) and Hf(IV)," J. Electron Spectrosc. Relat. Phenom. 234, 80-85 (2019).

${ }^{76}$ S. J. Randolph, J. D. Fowlkes, and P. D. Rack, "Focused, nanoscale electronbeam-induced deposition and etching," Crit. Rev. Solid State Mater. Sci. 31, 55-89 (2006). 